\title{
Teaching sustainable solutions in engineering
}

\section{Olsen, Stig Irving; Nielsen, Susanne Balslev; Ejlertsen, Marina; McAloone, Tim C.}

\section{Published in:}

International Journal of Innovation and Sustainable Development

Link to article, DOI:

10.1504/IJISD.2015.068788

Publication date:

2015

Document Version

Peer reviewed version

Link back to DTU Orbit

Citation (APA):

Olsen, S. I., Nielsen, S. B., Ejlertsen, M., \& McAloone, T. C. (2015). Teaching sustainable solutions in engineering. International Journal of Innovation and Sustainable Development, 9(2), 157-167. https://doi.org/10.1504/IJISD.2015.068788

\section{General rights}

Copyright and moral rights for the publications made accessible in the public portal are retained by the authors and/or other copyright owners and it is a condition of accessing publications that users recognise and abide by the legal requirements associated with these rights.

- Users may download and print one copy of any publication from the public portal for the purpose of private study or research.

- You may not further distribute the material or use it for any profit-making activity or commercial gain

- You may freely distribute the URL identifying the publication in the public portal

If you believe that this document breaches copyright please contact us providing details, and we will remove access to the work immediately and investigate your claim 
Olsen SI, Balslev Nielsen S, Ejlertsen ML, McAloone T, 2015: Teaching sustainability solutions in engineering. Int J Innovation and sustainable development Vol 9 (2).

DOI: 10.1504/IJISD.2015.068788

1

Associate professor Stig Irving Olsen, Corresponding author

Technical University of Denmark

DTU Management Engineering

Produktionstorvet 424

2800 Kgs. Lyngby

Denmark

siol@dtu.dk

$+4545254668$

Stig Irving Olsen is associate professor in sustainable production at DTU Management Engineering. He is primarily involved in sustainability assessment of technologies applying life cycle based assessment methodologies. He has been involved in a number of projects with considerable industry participation within varying technological fields (biofuels, recycling, nanotechologies). He is engaged in pursuing the dissemination of sustainability teaching throughout DTU and is currently pedagogical coordinator at the department. Stig is MSc in Biology from University of Copenhagen (1988) and received his $\mathrm{PhD}$ from the Technical University of Denmark in 1997 for his work in Life Cycle Assessment in chemical industries.

Susanne Balslev Nielsen

Technical University of Denmark

DTU Management Engineering

Produktionstorvet 424

2800 Kgs. Lyngby

Denmark

Copyright (C) 200x Inderscience Enterprises Ltd. 
Olsen et al.

Susanne Balslev Nielsen is associated professor at DTU Management Engineering and deputy in Centre For Facilities Management at the Technical University of Denmark. She is specialized in sustainability in the build environment and has written a large number of publications about integrating sustainability in Facilities Management, in urban development and infrastructure management. Her research addresses the needs of professionals and advances the knowledge about challenges and benefits of integrating the sustainability perspective in context specific engineering. In 2010 she received the award as European FM-researcher of the year. Susanne is educated as Civil Engineer (1993) and received her Ph.D. for her study of sustainable transformation of urban infrastructure.

Marina Ejlertsen

DTU Management Engineering

Produktionstorvet 424

2800 Kgs. Lyngby

Denmark

Marina Leisner Ejlertsen is a master student at DTU. She has a bachelor in Design and Innovation, which focus on product and system development based upon competences within basic engineering skills, sociotechnic and team based development projects. In the of summer of 2013 she began the master programme of Design and Innovation, with the ambition of focusing on sustainable product development and product/service-systems. Besides of her studies Marina works at Students Business Relations (DSE), which is a non-profit student organisation creating contact and interaction between Danish engineering students and the industry.

Tim McAloone

Technical University of Denmark 
Teaching Sustainable Solutions in Engineering

DTU Mechanical Engineering

Nils Koppels Allé

Bygning 404

2800 Kgs. Lyngby

Denmark

Tim McAloone is Professor of Product/Service-Systems at the Technical University of Denmark. He works closely with Danish industry, creating new methods and models for a wide range of product development issues, such as product/service-systems, sustainable design and product innovation. He has many research activities, including projects such as the Innovation Consortium "PROTEUS", which focuses on the creation of product/service innovation methodologies for the Danish maritime industry. Tim received his $\mathrm{PhD}$ from Cranfield University in 1998, where he studied the integration of eco-design strategies into industry. His first degree is in Mechanical Engineering from Manchester Metropolitan University in 1993. 
Olsen et al.

\title{
Teaching sustainable solutions in engineering
}

\section{Stig I. Olsen ${ }^{1 *}$, Susanne B. Nielsen ${ }^{1}$, Marina Ejlertsen ${ }^{1}$, Tim McAloone $^{2}$}

${ }^{1}$ Technical University of Denmark

DTU Management Engineering

Produktionstorvet 424

2800 Kgs. Lyngby

Denmark

${ }^{2}$ Technical University of Denmark

DTU Mechanical Engineering

Nils Koppels Allé

Bygning 404

2800 Kgs. Lyngby

Denmark

*Corresponding author

siol@dtu.dk

$+4545254668$

\begin{abstract}
The increasing societal and industrial emphasis on sustainability requests that the next generation engineers needs to be trained in the context of sustainability. One of the means to address students at DTU is the establishment of a course aimed at bachelor students from all of the university's study lines. The objectives of the course "Sustainability in engineering solutions", is for the participants to understand the basic concept of sustainability and its three dimensions (people, profit, planet), as well as to analyse problems and synthesise solutions that are sustainable throughout their life cycle. The course runs over a full time three week period and employs project-based learning with several subprojects/-problems.
\end{abstract}


This paper takes an in-depth discussion of the considerations concerning how to teach such a complicated subject to students of widely differing backgrounds, and reflects both the teachers' and the students' experiences with the course.

Keywords: Engineering education, curriculum, sustainability, project-based learning, integrating sustainability, core elements, learning objectives, pedagogical principles, bachelor, diversity of students, real life challenges

\section{Introduction}

Addressing the presently unsustainable development of the global society, engineering is generally seen as both a part of the problem as well as a part of the solution. Engineers seek to apply the knowledge of science to deliver practical solutions and have contributed to a large extent to the technology development that has led us to the current state of environmental unsustainability. It is thus crucial that sustainability is part of engineers' education. In addition, industry's concern of not meeting societal demands calls for a development towards sustainability awareness. Standardisation through governmental laws is forcing companies to think of sustainable alternatives and future regulations regarding stricter environmental standards for production systems may cause a paradigm shift in organisational culture, from voluntary participation to compulsory compliance. To be prepared for these fundamental changes, engineering firms must hire new talents, who are aware of the principles, methods and tools that can mitigate the environmental impact of products and production systems (Bernstein et al. 2012). The next generation of engineers therefore need to be trained in the context of sustainability, along with a global perspective, in order to solve the problems of sustainability on multiple scales (Ramani et al. 2010). Within a few years 'sustainable engineering' will eventually equate with 'good engineering' (Allenby et al. 2009) and sustainability will turn from "nice to know" to "need to know".

Sustainability has already found its way into the curricula of many engineering educations around the world (e.g. Perdan et al. 2000, Fenner et al. 2005, Allenby et al. 2009, Onuki and Mino 2009, Quinn et al. 2009, Segalas et al. 2009, Uwasu et al. 2009, McAloone 2007) and the importance of education in sustainability, 
Olsen et al.

especially for engineers, is illustrated by the emphasis on this topic around the world.

In the same vein the Technical University of Denmark (DTU) emphasises that sustainability must be taken seriously in both research and education. The president has addressed the issue by stating "DTU's approach to sustainability must be broad, scientifically well-founded and operational. In particular we should contribute to being able to objectively assess which of two solutions is the most sustainable - and to this being an ability that is nurtured in all engineering students" in his annual speech in 2012. Additionally, in the DTU strategy 20142019 developed by the board of governors it is stated that study programmes will be designed to ensure that sustainability is an integrated part of all programmes. However, this strategy has yet to be systematically implemented in all the educational programmes at the university. The dean of bachelor education addresses environmental sustainability by establishing a pan-university competition, where course leaders and students can opt to steer their course/course work in the direction of the "Groen Dyst" competition (green challenge, www.groendyst.dtu.dk). The aim of this initiative is to inspire teachers to address sustainability in their courses.

Another strategy, recently launched by the dean of bachelor education is to make more informed sustainability teaching integrated into courses by individual teachers on the different study lines, through providing the necessary knowledge via a "teach the teacher" programme. This programme is still only in the planning phase and there may be potential hurdles. Mulder et al. (2012) found similar initiatives in many universities, who estimated that their lecturers needed to be trained for integrating Sustainable Development (SD). However, "teach the teacher" projects were generally not very successful since teachers "hate being taught” (Mulder et al. 2012). It may be a consequence that the teaching has to be done by sustainability experts or at least supplemented by a generic course for students, as the one presented here.

This paper presents one approach to pursuing the strategy of educating engineers at DTU in sustainability through the development of a dedicated generic course on sustainability for all bachelor students. The course apply discipline oriented project based learning in an innovative way through partnering with local community actors (exemplified by a primary school and the campus service at DTU) thus maximising benefits for both students and local community. The pros and cons of 
different approaches and challenges of making a dedicated course are discussed later in the paper. A number of questions and challenges relate to the issue of teaching sustainability to engineering students, for example:

- Should the teaching in sustainability be integrated in several basic courses at each study line or can it be taught in a single dedicated course?

- If integrated: How is it ensured that teachers acquire the necessary sustainability competences?

- If a single course: What are the challenges of teaching students from several different study lines in the same course?

- Which pedagogical principles should be used?

A particular contribution of this paper to the literature is the discussion on ensuring that core elements are taught in discipline oriented projects.

\section{Dedicated course or integrated teaching?}

In the literature it is currently argued that if engineers are to contribute truly to sustainable development, sustainability must become part of their paradigm and affect the way they think (e.g. Holmberg et al., 2008). The best (and some claim the only) way to achieve this is through making sustainability an integral part of the curriculum and follow an integrated approach to teaching sustainability (e.g. Perdan et al., 2000). This means that sustainability teaching should be integrated into the regular engineering courses, in order to enable the students to integrate sustainability into their engineering practice and technical designs. The authors agree that it would be optimal if the students throughout their studies were taught to consider sustainability in everything they do. However, experience and research shows that there are several hurdles to this. Firstly, there is the set of factors dealing with the theoretical part of the curricula. SD is among most traditional engineers often looked upon as a less relevant consideration and a more "soft skill” than other parts already placed in the curriculum. Environmental considerations are also mostly categorised as something discussable rather than concrete solvable problems. For engineers, providing solutions is considered to be more important than analysing problems (Mulder et al. 2012). However the difficulties of integrating sustainability into the curriculum are mostly caused by barriers related to the organisation and the cultures of universities. 
Olsen et al.

The organisational culture's concern is about the procedure and university rules for the combination and content of the courses within the curricula. Research on integrating SD at TU-Delft showed that in most departments - and certainly within the mainstream core engineering courses - SD was just of no interest (Peet et al. 2004).

Academic culture deals with lecturers' resistance of being forced to teach beyond their scientific field. Experience from different projects at technical universities (TU Delft (NL), UPC (ES) and Chalmers (SE)) shows that the academic end engineering culture is relatively resistant to sustainability integration (Holmberg et al. 2008). Another perspective is that many lecturers take some pride in the tough character of their course. Demands of students for SD are often countered by the claim that this will lower the level of the course (Peet et al. 2004).

Engineering culture has the barrier of old tradition and the maintained opinion that e.g. mechanical engineering curricula is based on knowledge of fundamental engineering skills such as; mathematics, static and dynamic mechanics, material science and process technologies. All of this makes little room for analysing and implementing sustainability in the curricula.

There is no reason to assume that the cultures and barriers are different at DTU compared to the universities mentioned above. Being researchers in sustainability, the aim is of course to make as many students as possible aware of sustainability and to provide them with an incentive to pursue sustainability and critically evaluate their work in this respect. As a first approach it has therefore been chosen to establish a dedicated course in which the students are enabled, through the course structure and pedagogical principles, to integrate sustainability considerations into their continuing work.

\section{The generic course}

The course "Sustainability in engineering solutions" was initiated in 2011 as a cooperation between researchers within different aspects of sustainability: quantitative sustainability assessment; systematic design of sustainable solutions; and sustainability management. The course is designed as an introductory course for bachelor students (most are at the end of their second year) from all study lines at DTU. The course is an elective and there is no compulsory follow up activities in courses later in their study, but it is of course our hope that the students apply 
their learnings in other projects . Currently, there are 15 different bachelor study lines at DTU with very different technical foci, e.g. software technology, medicine and technology, building design, etc. This diversity involves a challenge of making the course relevant to all students, an issue that will be discussed in more detail later. The course is in its early development and has just 18, 22, and 27 students, in 2011, 2012, and 2013 respectively.

The course is a 5 ECTS point course, running in a three-week period, where the students work 40 hours per Week, exclusively on the one course. This structure of the course encourages the students to go in depth with the topic. Obviously, the pedagogical approach must suit the structure as discussed below. The general course objectives are described in the remainder of this paragraph. The participants should acquire an understanding of the basic concept of sustainability and its three dimensions. They should acquire an overview of a number of tools for analysis and synthesis of solutions that are sustainable throughout their life cycle - from cradle to grave - and acquire the skills to use the most central of the tools. Furthermore, they should understand the engineer's role and responsibility in the development of sustainable solutions.

Table 1 gives an overview of the core elements and the expected learning outcomes from the course. The coverage of all levels in Bloom's taxonomy aims to enable the students to use tools regarding SD and later apply these in engineering practice.

The overarching pedagogical approach is project based learning (PBL) and most of the three weeks the students do their own project work. The first introductory day is mostly lectures about introduction to the course, to sustainability and to the project work. On the second day students are organised into groups and hereafter they choose their topic, prepare for field work and carry out the initial field work. Throughout the remainder of the two first weeks theories are presented in the mornings, mixed with exercises related to the project and the afternoons are dedicated to project work, with access to supervision every day. The third week is mainly project work with supervision. During the second week 3-5 invited lectures from industry and NGO's present how sustainability plays a role in their organisation.

Student feedback to the teaching is collected partly through a formalised anonymous web-based evaluation scheme and partly through an informal 
Olsen et al.

discussion session at the end of the course taken point of origin in the answers to the web-based evaluation.

Table 1: Core elements and learning outcomes (Bloom's taxonomy (BT) for cognitive learning (1-Knowledge, 2-Comprehension, 3-Application, 4-Analysis, 5-synthesis and 6-Evaluation))

\begin{tabular}{|c|c|}
\hline Core elements & Learning outcomes (the student will be able to....) \\
\hline $\begin{array}{ll}\text { - } & \text { Absolute sustainability } \\
\text { vs. relative } \\
\text { sustainability } \\
\text { - } \quad \text { Life cycle thinking and } \\
\text { simplified tools } \\
\text { - } \quad \text { DPSIR (Driving forces } \\
\text { - Pressures - Stressors } \\
\text { - Impacts - } \\
\text { Responses) } \\
\text { - } \quad \text { Ideal concepts and } \\
\text { negative brainstorm } \\
\text { - } \text { Actor network analysis } \\
\text { Sustainability } \\
\text { management (strategy, } \\
\text { implementation, } \\
\text { suppliers, innovation } \\
\text { etc.) }\end{array}$ & $\begin{array}{l}\text { Describe the three dimensions of } \\
\text { sustainability (BT-1 and -2) } \\
\text { - Explain that each dimension is multifactorial } \\
\text { and that trade-offs exist within and between } \\
\text { them (BT-1 and -2) } \\
\text { - Illustrate how companies can work towards } \\
\text { the development of sustainable solutions (BT- } \\
\text { 2) } \\
\text { - Describe the product chain perspective (BT-1 } \\
\text { and -3) } \\
\text { - Know and use various simplified tools for use } \\
\text { in sustainability assessment (BT-1 and -3) } \\
\text { - Explain that assessments imply integrated } \\
\text { sensitivity assessments and iterations (BT-4) } \\
\text { - Master the analysis of solutions using life } \\
\text { cycle thinking (BT-4) } \\
\text { Master the synthesis of solutions using ideal } \\
\text { concepts in product development (BT-5) } \\
\text { - Be able to relate critically to the results of } \\
\text { various tools (BT-6) }\end{array}$ \\
\hline
\end{tabular}

\section{Pedagogical considerations}

As mentioned the overall pedagogical approach throughout the course is PBL performed in group work. Following the three types of projects defined by de Graff \& Kolmos (2003) the projects are discipline projects where the methods have more or less been prescribed by the teachers but still allow the students to define the problem within the guidelines of the prescribed disciplines. The problem is partly defined since there are a number of subjects they can choose from, but they have to perform their own analysis, in order to understand what the problem (or potentially several problems) is. There are several good reasons for this choice.

- Project based learning requires the application of knowledge acquired from lectures and exercises in the course. 
- The group work facilitates reflections of the students own understanding because of variation within the group - active discussions motivates students to learn.

- A project calls for the students to formulate solutions and to re-evaluate their approach in response to the outcomes of their efforts.

- A project resembles the challenges that the students are likely to encounter in other projects both later in their studies and in their professional life.

- Involving students through project based learning dealing with relevant problems encourages them to look critically on their own projects and enable them to apply the gained knowledge in future projects. However, de Graff \& Kolmos (2003) note a common difficulty in transferring the methods and skills acquired in one project to another project, which may be a pitfall that we need to consider.

- And last but not least, the course structure (i.e. three weeks full time) encourages a teaching approach where students are active with their own work.

However, there is also a risk that students working on different problems/subjects are not offered the same learning opportunities since there will be different focus areas in each project. Presence of at least one teacher throughout the course and daily supervision of each group helps the students with guiding the problem definition, steering the students to do the right tasks, and finally to present the project. Based on the students' feedback the accessibility of the teachers for supervision is important for the learning. Additionally, an early presentation of what is expected content-wise in the final report of the groups helps the students to focus on the right tasks.

Throughout the second half of the course the groups present different milestones (partly defined by the teachers) in a total of four presentations (a mix of posters and slideshows). There are multiple purposes of the presentations: The groups learn from each other's approaches and get peer feedback, it helps the students to plan and prioritise their project work in the relatively short time horizon of the course and it forms part of the assessment of the students.

The assessment of the students is performed according the Danish 7-step grading system. Practical, analytical and interpretative learning outcomes are assessed via evaluation of the project deliverables. Main emphasis is on the written material but the presentations during the course counts as well. Additionally, for assessing the 
Olsen et al.

lower levels of cognitive learning (in Bloom's taxonomy) a multiple choice test is performed on the last day of the course.

\section{Choice of projects}

The course has been run three times, with two different types of projects each with different strengths and weaknesses. The first year projects were to a large extent chosen based on the methods taught in the course, whereas the second and third year projects were based on real life problems. All years groups were formed based primarily on the students' own interests in the different projects.

The methods applied in the course are to a large extent life cycle based environmental assessments and product/system design improvement methods. In the first year of the course, the projects were chosen as to be good examples of problems in this area. A number of everyday appliances were acquired (mainly electric appliances) and the students were given the task to optimise the products from an environmental perspective. They were allowed to disassemble (and destroy) the products in order to identify materials, technical construction etc. These projects worked very well for a number of the core elements of the course but especially the sustainability management part was difficult to integrate sufficiently. Furthermore, a number of the students found that it was difficult to relate the projects to their respective study lines.

In the second year of the course another approach was therefore chosen. The whole course got the theme "the sustainable primary school", meaning all projects in the course contributed to that the overall aim. "Lundtofte Skole" which is a municipal primary school nearby DTU agreed to participate as case and was represented by staff at several of the students' presentations. The school heads predefined a number of projects (heating, water use/supply, use of electronics, cleaning, and ventilation, plus a number more that were not chosen by the students), where the students should aim to provide suggestions for environmental improvements. The aim was to identify a sufficient diversity of project in order for most students to feel that it could be relevant to their study line. In this respect these projects were successful, compared to the previous year and the student motivation was higher since the project concerned "real life" problems and the school would perhaps use their suggestions. However, in some of the projects (e.g. water use) it was difficult to work in-depth with several of the core elements of the course (e.g. life cycle thinking and simplified tools). 
In the third year the theme was "the sustainable campus" and the DTU campus service already had many topics where they wondered which would be the most sustainable solution. This year there were more topics to choose from and more emphasis was put on identifying those that could support the core elements of the course better. Additionally, the third year the teaching in sustainability management was made more concrete in terms of giving more specific guidance in each individual project. Overall, it was found that the students' results in relation to the learning outcomes actually improved.

The main conclusion from the experiences with different types of projects is that the theme-based projects worked very well in terms of both student motivation and in terms of diversity of projects. The challenge is to be cautious in defining projects that make it possible to work with all core elements of the course. The main criterion for selection of projects is that they should not be too complex. A number of criteria are in principle related to this: 1) The students should be able to define a problem that they can aim to solve within the three week period. 2) They should be able to overview the actor-network and understand what is needed to implement the solution. 3) It must be possible to identify the service the system provides to society and to identify the life cycles of competing systems to deliver the service. 4) It must be possible to identify/develop and discuss different solution. Furthermore, as mentioned above, the projects should be controlled by the teachers through frequent supervision to ensure that all students are able to reach the learning outcomes.

Especially the theme "the sustainable campus" could be an interesting theme to investigate for other universities aiming to implement comparable courses. The students, based on their feedback, found this theme to be very relevant since it relates to the daily life on campus, and it was easy to get in contact with the different actors. To establish such cases requires planning well ahead to raise the interest with the campus responsibles, identify relevant projects, and prepare the technical staff.

\section{Diversity of students - challenge or benefit?}

As mentioned previously DTU has 15 different bachelor study lines with a great diversity in the technical content. If the dedicated course should have any 
Olsen et al.

possibility to make an impact on the students' way of thinking about their projects, the course must be relevant and transferable to their own field of engineering.

In the first year there were 18 students attending from 8 different study lines: Design \& Innovation, Production \& Engineering Design, Mechanical Engineering, Building Design/Civil Engineering, Environment, Biotechnology, and Mathematical Modelling. In the second year there were 22 students from 10 different study lines, which were the same as above excl. Mathematical Modelling and incl. Chemistry, Arctic Technology, and Medicine \& Technology. The third year we had 27 students from 13 different study lines (one of them a master student).

Based on the students' feedback several of them found it difficult to relate the projects to their own technical field the first year where the projects were very product-oriented. In the second year, the vast majority of the students were able to find a project they found relevant (although the group with chemists, who chose a project on cleaning services had severe difficulties finding data to perform their project). The third year almost all students found a project that they found relevant, but an important feedback was also that they actually didn't find it important which topic they were working on since the main outcome of the course is the general understanding of sustainability and the skills to perform analyses with the tools and methods presented.

Another assumed challenge is to find the right level of teaching the theoretical content, due to the different level of understanding of sustainability amongst students. This has turned out not to be an issue, since the feedback of those students that already had some knowledge illustrated an appreciation of the way theories were presented.

In their feedback many students further specifically mentioned the benefits of working together with students from other study lines, since this gave insight into another technological field, another way of working with projects, and because they contributed with different inputs to the project work.

Currently the ambition for the course is to continue the collaboration with a new local partner each year, to ensure the realism in the student tasks and to further emphasise the societal value of the student work, by letting the partner organisation benefit from the students' analyses and suggestions for improvements. In a first 
instance DTU Campus service has found it tremendously worthwhile to cooperate with the students and they have offered to serve as case next year as well.

\section{Conclusion}

As part of a strategy to introduce sustainability to all students a dedicated course for bachelor students has been initiated. It addresses students at all study lines and aims to introduce sustainability and to encourage the students to look critically on their own projects and to enable them to apply the gained knowledge in future projects. For this purpose project based learning is used. It is, however, challenging to identify good projects in which students can work in depth with all core elements, at the same time being relevant to the diversity of technical fields of the students. However the very positive aspect of the diversity is that in their course evaluations the students appreciate the mix of different study lines which ensures the contribution of different types of inputs to their work.

The students generally answer that they learn a lot in the course and that the combination of theory and practice in the form of own work on cases with supervision is a good way of introducing the topic and to practice sustainability evaluations and innovation in engineering education.

It is generally recognised that embedding sustainability within the curriculum does not only mean including new content. If engineers are to truly contribute to sustainable development, sustainability must become part of their paradigm and affect their everyday thinking. This, on the other hand, can only be achieved if sustainability becomes an integral part of engineering education programmes, not a mere 'add-on' to the 'core' parts of the curriculum. However, there are both organisational and cultural barriers of making sustainability an integral part of the programme.

To what extent the course described has an impact on the students' approach to integrate sustainability in their future academic path has not been investigated. As a future work on this topic it would be interesting to follow up with a questionnaire to all previous students at the course. 
Olsen et al.

\section{References}

Allenby B., Murphy C.F., Allen D. and Davidson C., 2009. Sustainable engineering education in the United States. Sustainability Science, 4:7-15.

Bernstein WZ, Ramanujan D, Zhao F, Ramani K and Cox MF, 2012: Teaching design for environment through critique within a project-based product design course. International Journal of Engineering Education, 28(4), pp. 799-810.

De Graff E \& Kolmos A, 2003: Characteristics of problem based learning. Int. J. Engng. Ed. Vol. 19 (5) pp. 657-66

Fenner R.A., Ainger C.M., Cruickshank H.J. and Guthrie P.M., 2005. Embedding sustainable development at Cambridge University Engineering Department. International Journal of Sustainability in Higher Education, 6:229-241.

Holmberg J, Svanstrom M, Peet D-J, Mulder KF, Ferrer-Balas D and Segalas J, 2008. Embedding sustainability in higher education through interaction with lecturers: case studies from three European technical universities. European Journal of Engineering Education, 33(3), pp. 271-282.

Mulder KF, Segalas J, and Ferrer-Balas D, 2012. How to educate engineers for/in sustainable development: Ten years of discussion, remaining challenges. International Journal of Sustainability in Higher Education, 13(3), pp. 211-218.

Onuki M. and Mino T., 2009. Sustainability education and a new master's degree, the master of sustainability science: the Graduate Program in Sustainability Science (GPSS) at the University of Tokyo. Sustainability Science, 4:55-59.

Perdan S., Azapagic A. and Clift R., 2000. Teaching sustainable development to engineering students. International Journal of Sustainability in Higher Education, $1: 267-279$

Peet D-J, Mulder KF and Bijma A, 2004. Integrating SD into engineering courses at the Delft University of Technology: The individual interaction method. International Journal of Sustainability in Higher Education, 5:278-288. 
McAloone, T.C., 2007. A Competence-Based Approach to Sustainable Innovation Teaching, Experiences within a New Engineering Programme. Journal of Mechanical Design, 129(7), ASME, pp. 769-778. ISSN 1050-0472.

Quinn S., Gaughran W. and Burke S., 2009. Environmental sustainability in engineering education - Quo Vadis? International Journal of Sustainable Engineering, 2:143-151.

Ramani, K., Zhao, F., Ramanujan, D., Bernstein, W.Z., Sutherland, J., Handwerker, C., Choi, J., Kim, H., and Thurston, D., 2010. Integrated sustainable life cycle design: A Review. Journal of Mechanical Design, Transactions Of the ASME, 132(9), pp. 0910041-09100415.

Segalas J., Ferrer-Balas D., Svanström M., Lundqvist U. and Mulder K.F., 2009. What has to be learnt for sustainability? A comparison of bachelor engineering education competences at three European universities. Sustainability Science, $4: 17-27$.

Tam E.K.L., 2007. Part I - Educating Students in Sustainable Engineering (II) Developing a Sustainability Course for Graduate Engineering Students and Professionals. International Journal of Engineering Education, 23:1133.

Uwasu M., Yabar H., Hara K., Shimoda Y. and Saijo T., 2009. Educational initiative of Osaka University in sustainability science: mobilizing science and technology towards sustainability. Sustainability Science, 4:45-53. 